\title{
Impact of Neoadjuvant Chemotherapy Interval on Tumour Regression Grading for Rectal Cancer
}

\author{
Thomas Tiang, MBBS, FRACS ${ }^{*}$, Ankur Sidhu, MBBS, FRACS ${ }^{2}$, David Williams, MBBS, FRCPA and \\ Andrew Bui, MBBS, FRACS ${ }^{1,2}$ \\ ${ }^{1}$ Department of Colorectal Surgery, Austin Health, Australia \\ ${ }^{2}$ Department of Colorectal Surgery, Northern Health, Australia \\ ${ }^{3}$ Department of Anatomical Pathology, Austin Health, Australia

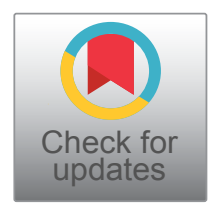

*Corresponding author: Thomas Tiang, MBBS, FRACS, Department of Colorectal Surgery, Austin Health, St. Vincent's Hospital, 41 Victoria Parade, Fitzroy, VIC 3065, Australia, Tel: 0415579676

\begin{abstract}
Background: The rectum is the site of $30 \%$ of all colorectal tumours. When contemplating neoadjuvant alternatives and surgical treatments, the rectum's position within the bony pelvis and its closeness to important tissues offer major therapeutic difficulties. Colorectal cancer survival times have improved as a result of advances in primary and adjuvant treatments. This paper aims to investigate the tumour regression grade (TRG) in rectal cancer patients, primarily if the interval of surgery after neoadjuvant chemoradiotherapy (nCRT) impacts tumour regression grade.
\end{abstract}

Methodology: The data of this retrospective study was obtained from Austin and Northern hospitals, Australia. Patients with biopsy-proven adenocarcinoma in the rectum who completed neoadjuvant chemotherapy with infusional 5-FU based chemotherapy and long-course radiotherapy or Short course radiotherapy were included. The $R$ Statistical Computing Package was used for data analysis. A P-value of $<0.05$ was considered significant.

Results: From the data of 114 patients, Data of 61 patients was analyzed in which $62.3 \%(n=38)$ were males. $85.24 \%$ $(n=52)$ were more than 50 years, whereas the participant's mean age was $63.39 \pm 14.21$. In terms of complete pathological response, no significant difference has been observed in individuals who have undergone surgery within 9 weeks or after 9 weeks $(P=0.459)$. And those who have undergone short and long term radiotherapy $(p=0.703)$. No significant association was observed in multinomial logistic regression with tumor regression grade except female gender, with a p-value of 0.043 for TRG 2 .

Conclusion: This study shows that interval to surgery has had no statistically significant effect on tumor regression grading for this cohort.

\section{Introduction}

Colorectal cancer (CRC) is the $2^{\text {nd }}$ most deadly tumour globally and is considered the $3^{\text {rd }}$ most prevalent malignant tumour, and its prevalence is gradually increasing in emerging countries. A recent study reported nearly 2 million new CRC cases, with 0.8 million deaths, accounting for over $10 \%$ of all new cancer cases and deaths globally, and it is estimated that the figure of new cases is will reach $25,000,000$ by $2035[1,2]$.

It is the $3^{\text {rd }}$ most prevalent cancer reported in Australia in 2017, It was reported in 67.3 and 49.4 per 100,000 in men and women respectively [3]. Obesity and sedentary lifestyle, tobacco smoking, beef and processed meat intake, and ionising radiation exposure are related with an increased risk of colorectal cancer [4].

Studies have reported the improvement in the survival time of colorectal cancer due to advancements in primary and adjuvant therapies. The optimum CRC treatment is to completely remove the tumor and all of its metastases, which usually necessitates surgery [5]. Regardless of the existence of various screening and diagnostic approaches aimed at lowering CRC incidence, around $25 \%$ of CRCs are detected at a terminal stage with metastases, and one-fifth of the remaining cases may progress to metachronous metastases, posing challenges for curative surgical control and resulting in tumour-related deaths [6].

Citation: Tiang T, Sidhu A, Williams D, Bui A (2022) Impact of Neoadjuvant Chemotherapy Interval on Tumour Regression Grading for Rectal Cancer. Int J Surg Res Pract 9:137. doi.org/10.23937/23783397/1410137

Accepted: January 28, 2022; Published: January 30, 2022

Copyright: (C) 2022 Tiang T, et al. This is an open-access article distributed under the terms of the Creative Commons Attribution License, which permits unrestricted use, distribution, and reproduction in any medium, provided the original author and source are credited. 
The standard of care for locally advanced rectal cancer (stages cT3-4/Nx or cTx/N1-2) is neoadjuvant chemoradiotherapy (NCRT) followed by radical total mesorectal excision (TME) with or without adjuvant chemotherapy [7,8]. Despite the widespread use of neoadjuvant CRT in the treatment of rectal cancer patients, the best time for surgery following neoadjuvant therapy is still unknown and has been a topic of discussion in rectal cancer treatment and management [9]. The rationale for extending time intervals to surgery has been to allow the cumulative effect of radiotherapy to destroy remaining tumour cells in the rectum and surrounding tissues.

Neoadjuvant chemoradiotherapy for locally advanced rectal cancer has been established as the standard of care worldwide, but controversies have arisen regarding the interval to surgery after completion of chemoradiotherapy. Tumour regression grading has been shown to provide useful prognostic information on tumour biology, disease-free and overall survival. However, interval to surgery after completion of neoadjuvant therapy has not been standardised. Studies in the literature have demonstrated an increased complete pathological response when extending the interval to surgery beyond 8 weeks $[10,11]$, other studies showing conflicting results [12].

Several randomised control trials have investigated the effect of interval after nCRT, such as the GRECCAR6 trial, which shows no statistically significant difference in long-term outcomes from 7-11 weeks interval [12].

The purpose of this study is to see if the interval between surgeries after nCRT affects tumor regression grade in rectal cancer patients.

\section{Methodology}

\section{Study design}

This descriptive retrospective study was performed on the data collected from 2009-2015.

\section{Setting}

Data was collected from Austin and Northern hospitals, Australia.

\section{Inclusion and exclusion criteria}

The inclusion criteria for this study were patients treated across the Austin and Northern Health Services that had biopsy-proven adenocarcinoma in the rectum. Primary outcomes being the tumour regression grade of the rectal specimen. Data of 114 Patients across the two health services were assessed with biopsy-proven rectal adenocarcinoma. Of these 61 patients had locally advanced rectal cancer and had either short course radiotherapy or long course chemoradiotherapy in the neoadjuvant setting. Patients were discussed in a Multi-disciplinary Meeting with a dedicated Colorectal Radiologist reporting pre-operative MRI scans to determine pre-operative $\mathrm{T}$ and $\mathrm{N}$ stage, guiding the decision regarding administration of neoadjuvant therapy.

\section{Intervention}

Patients completed neoadjuvant chemotherapy with infusional 5-FU based chemotherapy and long-course radiotherapy being 50 Gy of radiotherapy over 25 fractions. Patients then proceeded to a Total mesolectal excision of the rectum either with or without sphincter preservation. Short course radiotherapy involved 25 Gy administered over 5 days with the median interval to surgery for short course radiotherapy being 7 weeks. A dedicated anatomical pathologist performed histological examination with tumor regression grading completed for the majority of specimens with the modified Ryan grading system.

This is described in Figure 2.

\section{Statistical analysis}

For data entry and analysis, the $\mathrm{R}$ Statistical Computing Package was used. Demographic and Clinical characteristics are measured in frequency and percentages. Fisher's Exact Test was used to explore the association of complete pathological response (PCR) with time interval i.e. $<9$ weeks vs. $\geq 9$ weeks, and Short and the long course of radiography. Logistic Regression modeling was utilized in this dataset with tumor regression grade being the primary outcome. Analysis was performed using the $\mathrm{g} / \mathrm{m}$ (generalised linear modelling) function in the R statistical computing package. Modeling included Age, Gender, Location of Tumour, Operation performed, type of radiotherapy, and interval to surgery ( $<9$ weeks vs. $\geq 9$ weeks) as factors.

\section{Ethical approval}

The ethical approval was sought through the Austin Health Human Research Ethics Committee, HREC reference LNR-17-Austin/142.

\section{Results}

The current study data of 114 patients COLLECTED from the two health services with biopsy-proven rectal adenocarcinoma was found. Data of 61 patients were analysed. In the current study $62.3 \%(n=38)$ were males, $85.24 \%$ ( $n=52$ ) were 51 year or more. Mean age of the participant was $63.39 \pm 14.21$ (Minimum $=25$ years, Maximum $=88$ years) Data of 53 patients were excluded because 30 patients with early rectal cancer not undergoing nCRT, 14 patients were palliated, not undergoing TME, 8 patients had to watch and wait. This is summarised in the CONSORT diagram Figure 1. Due to the pacemaker, MRI of 4 patients was not available, and 2 patient's MRI was not present on the system (in the records). TME rectal dissection before 9 weeks was performed in 23 patients and 36 individuals were 
CONSORT DIAGRAM

흏

高

\section{Consort Diagram}

Enrollment

Allocation

Analysis

\section{Assessed for eligibility \\ ( $\mathrm{n}=65$ Austin Health, 49 Northern Health) \\ $\mathrm{N}=114$}

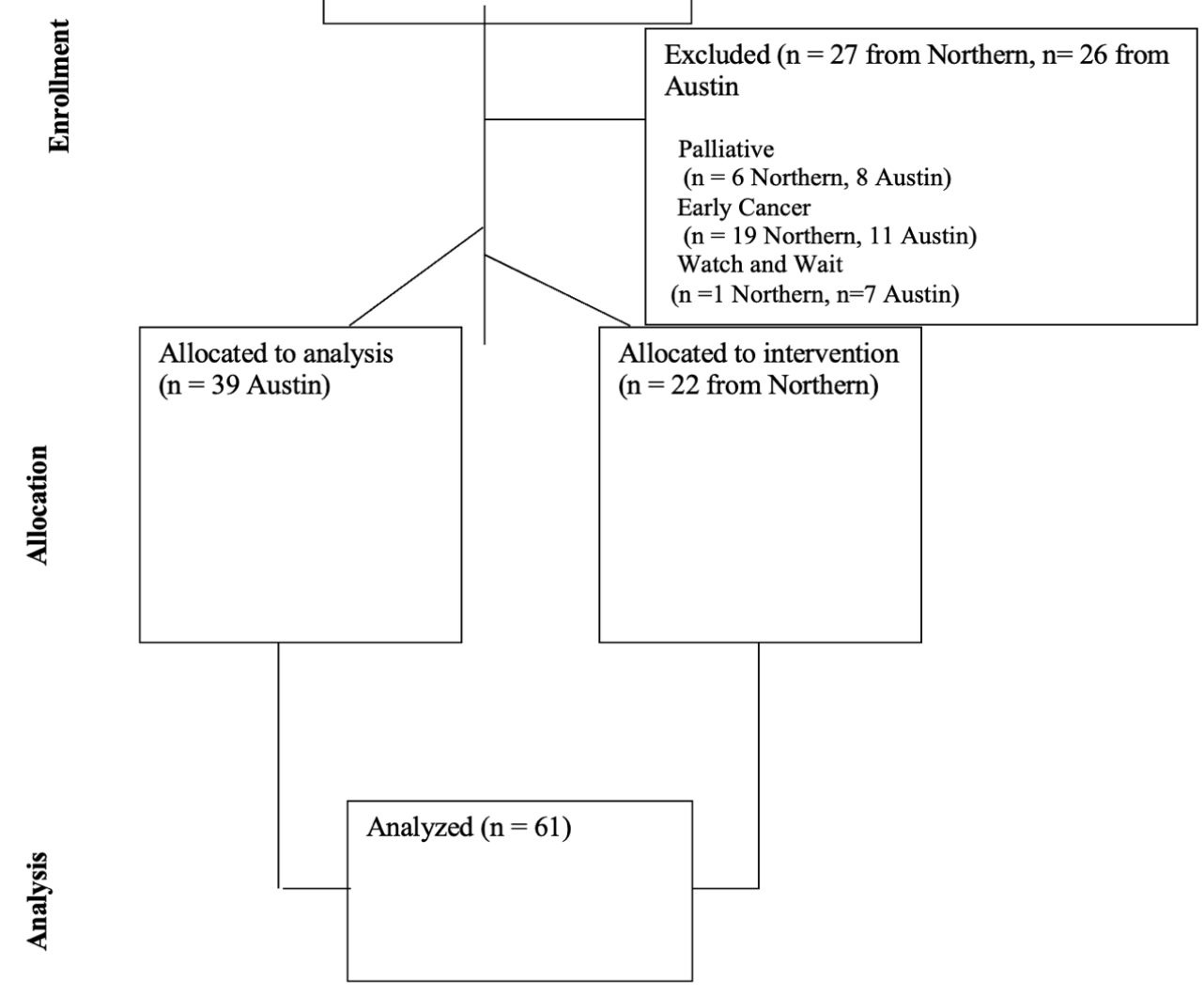

Excluded ( $n=27$ from Northern, $n=26$ from

Palliative

( $\mathrm{n}=6$ Northern, 8 Austin)

Watch and Wait

$(\mathrm{n}=1$ Northern, $\mathrm{n}=7$ Austin $)$

Assessed for eligibility $(n=65$

Austin Health, 49 Northern

Health)

$\mathrm{N}=114$
Excluded $(\mathrm{n}=27$ from Northern, $\mathrm{n}=26$ from Austin

Palliative ( $\mathrm{n}=6$ Northern, 8 Austin)

Early cancer ( $\mathrm{n}=19$ Northern, 11 Austin)

Watch and wait $(\mathrm{n}=1$ Northern, $\mathrm{n}=7$ Austin)

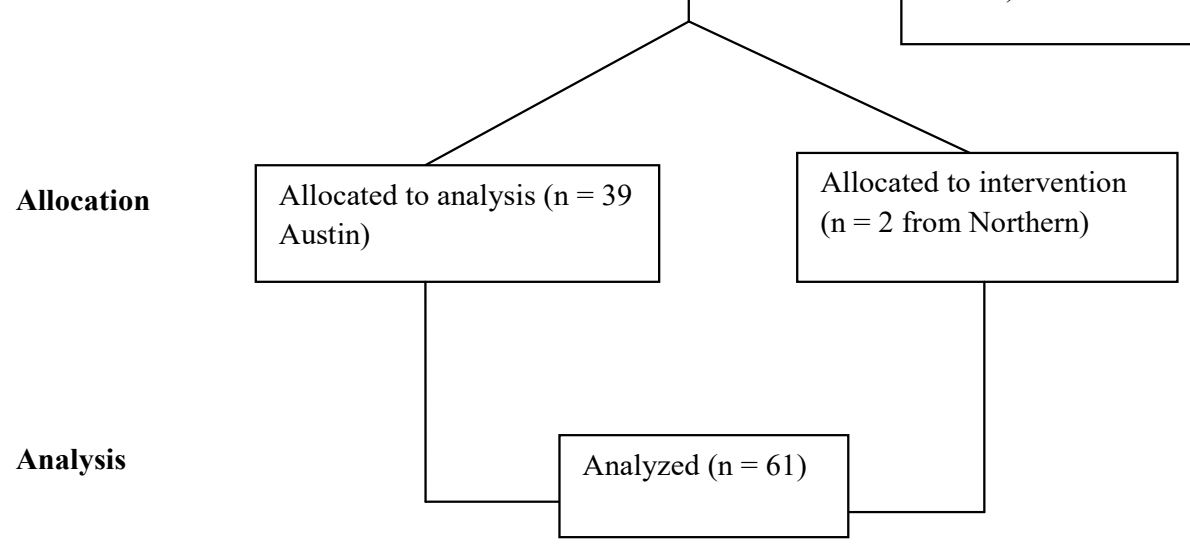

Figure 1: CONSORT diagram showing study design. 


\begin{tabular}{c|c|}
\hline Description & $\begin{array}{c}\text { Three-point } \\
\text { TRG }\end{array}$ \\
\hline $\begin{array}{c}\text { No viable cancer } \\
\text { cells }\end{array}$ & 0 \\
\hline $\begin{array}{c}\text { Single cells or } \\
\text { small groups } \\
\text { of cancer cells }\end{array}$ & 1 \\
\hline $\begin{array}{c}\text { Residual cancer } \\
\text { outgrown by } \\
\text { fibrosis }\end{array}$ & 2 \\
\hline $\begin{array}{c}\text { Significant fibrosis } \\
\text { outgrown } \\
\text { by cancer }\end{array}$ & 3 \\
\hline
\end{tabular}

Figure 2: Modified Ryan grading for tumour regression grading [23].

Table 1: Characteristics of the participants.

\begin{tabular}{|c|c|c|}
\hline Variable & $\mathbf{N}$ & $\%$ \\
\hline \multicolumn{3}{|l|}{ Gender } \\
\hline Male & 38 & 62.3 \\
\hline Female & 23 & 37.7 \\
\hline \multicolumn{3}{|l|}{ Age group } \\
\hline Upto 50 & 9 & 14.75 \\
\hline 51 and Above & 52 & 85.24 \\
\hline \multicolumn{3}{|l|}{ Hospital } \\
\hline Austin & 39 & 63.9 \\
\hline Northern & 22 & 36.1 \\
\hline \multicolumn{3}{|c|}{ Location of the tumor } \\
\hline Low & 35 & 57.4 \\
\hline Mid & 20 & 32.8 \\
\hline Upper & 5 & 8.2 \\
\hline Invalid & 1 & 1.6 \\
\hline \multicolumn{3}{|c|}{ Mri staging $\mathrm{T}$ before } \\
\hline Pacemake (NA) & 4 & 6.6 \\
\hline T2 & 12 & 19.7 \\
\hline T3 & 38 & 62.3 \\
\hline T4 & 5 & 8.2 \\
\hline Invalid & 2 & 3.3 \\
\hline \multicolumn{3}{|c|}{ MRI staging $\mathrm{N}$ after } \\
\hline Missing (NA) & 7 & 11.5 \\
\hline NO & 14 & 23.0 \\
\hline N1 & 27 & 44.3 \\
\hline N2 & 13 & 21.3 \\
\hline
\end{tabular}

undergone TME rectal dissection at or after 9 weeks. We analysed that $65.57 \%$ ( $n=40 / 61$ ) of patients completed long course neoadjuvant chemo-radiotherapy, the remainer undergoing short course radiotherapy. Tumour regression grading was completed for the $91.80 \%$ ( $n=$ $56 / 61$ ) with the modified Ryan grading system (Figure 2 ).

$14.8 \%(n=9 / 61)$ patients had complete pathological response which is similar to reported figures in the literature [8] (Table 1).

We analyse the difference of complete pathological response (PCR) among the individuals who have undergone surgery within 9 weeks (Group A) with the individuals who have undergone surgery at or after 9 weeks (Group B). PCR was observed in $9.09 \%(n=2)$ of

\begin{tabular}{|c|c|c|}
\hline \multicolumn{3}{|l|}{ Operation } \\
\hline APR & 11 & 18.0 \\
\hline AR & 1 & 1.6 \\
\hline Hartmann & 2 & 3.3 \\
\hline LapAPR & 8 & 13.1 \\
\hline LapAR & 8 & 13.1 \\
\hline LapULAR & 21 & 34.4 \\
\hline TEMS & 3 & 4.9 \\
\hline ULAR & 6 & 9.8 \\
\hline Missing & 1 & 1.6 \\
\hline \multicolumn{3}{|l|}{ Pathological T } \\
\hline TO & 9 & 14.8 \\
\hline T1 & 4 & 6.6 \\
\hline T2 & 16 & 26.2 \\
\hline T3 & 27 & 44.3 \\
\hline $\mathrm{T} 4$ & 3 & 4.9 \\
\hline Missing & 2 & 3.3 \\
\hline \multicolumn{3}{|l|}{ Pathological N } \\
\hline NO & 43 & 70.5 \\
\hline N1 & 12 & 19.7 \\
\hline N2 & 4 & 6.6 \\
\hline Missing & 2 & 3.3 \\
\hline \multicolumn{3}{|l|}{ TRG } \\
\hline 0 & 9 & 14.8 \\
\hline 1 & 21 & 34.4 \\
\hline 2 & 15 & 24.6 \\
\hline 3 & 11 & 18.0 \\
\hline Missing & 5 & 8.2 \\
\hline \multicolumn{3}{|l|}{ TME rectal dissection } \\
\hline Less Than 9 weeks & 23 & 37.7 \\
\hline 9 weeks or More Than 9 & 36 & 59.0 \\
\hline Local resection & 2 & 3.3 \\
\hline \multicolumn{3}{|l|}{ Radiotherapy } \\
\hline Long course & 40 & 65.6 \\
\hline Short course & 20 & 32.8 \\
\hline Missing & 1 & 1.6 \\
\hline
\end{tabular}


Table 2: Complete pathological response according to the surgical interval.

\begin{tabular}{|l|l|l|l|l|}
\hline $\begin{array}{l}\text { Complete pathological } \\
\text { response }\end{array}$ & $\begin{array}{l}\text { Interval surgery }<\mathbf{9} \\
\text { weeks }\end{array}$ & $\begin{array}{l}\text { Interval to surgery } \mathbf{2} \text { 9 } \\
\text { weeks }\end{array}$ & Chi square, P-value & Fisher's exact test \\
\hline Yes & $2(9.09 \%)$ & $7(19.44 \%)$ & $X^{2}=1.11,0.291$ & $P=0.459$ \\
\hline No & $20(90.90 \%)$ & $29(80.55 \%)$ & & 58 \\
\hline Total & 22 & 36 & & \\
\hline
\end{tabular}

Table 3: Short and long term radiotherapy response.

\begin{tabular}{|l|l|l|l|l|}
\hline $\begin{array}{l}\text { Complete pathological } \\
\text { response }\end{array}$ & $\begin{array}{l}\text { Short course } \\
\text { radiotherapy }\end{array}$ & $\begin{array}{l}\text { Long course } \\
\text { radiotherapy }\end{array}$ & Chi Square, P-value & Fisher's exact test \\
\hline Yes & 2 & 7 & $X^{2}=0.728,0.695$ & $P=0.703$ \\
\hline No & 17 & 32 & & 58 \\
\hline Total & 19 & 39 & & \\
\hline
\end{tabular}

Table 4: Multivariable logistic regression analysis of factors predicting a complete pathological response.

\begin{tabular}{|c|c|c|c|c|}
\hline \multirow[t]{3}{*}{ Variable } & \multicolumn{4}{|c|}{ TRG } \\
\hline & 0 & 1 & 2 & 3 \\
\hline & \multicolumn{4}{|l|}{ p-values } \\
\hline Age & 0.0950454 & 0.06771895 & 0.06252246 & 0.1706165 \\
\hline Gender & 0.13189424 & 0.15848806 & 0.04351153 & 0.8954164 \\
\hline Interval surgery (weeks) & 0.26220481 & 0.36536117 & 0.25552325 & 0.8852041 \\
\hline Long course radiotherapy & 0.0859002 & 0.10362699 & 0.06613691 & 0.2428285 \\
\hline Short course radiotherapy & 0.28750146 & 0.10306972 & 0.23955874 & 0.2360323 \\
\hline Restorative resection & 0.09651311 & 0.06383882 & 0.12746548 & 0.2047448 \\
\hline Non-restorative resection & 0.16147961 & 0.1256344 & 0.07687009 & 0.2443389 \\
\hline
\end{tabular}

the cases in Group A and 20\% ( $n=7)$ in group B. Using Fisher's Exact test, we found that the difference is not significant $(P=0.459)$ (Table 2).

We found that Complete Pathological Response was observed in $15.51 \%$ ( $n=9 / 58$ ) cases, including $11.11 \%$ $(n=2)$ cases of short-course radiotherapy and $22.58 \%$ $(n=7)$ cases of long course radiotherapy. Using Fisher's Exact test, we found no significant difference in both groups $(p=0.703)$ (Table 3$)$.

Multinomial Logistic Regression modelling was performed on the dataset with the model fitted as outlined in the analysis. Tumour Regression grading being the response variable and interval to surgery as well as other explanatory variables being fitted to this model are summarised in Table 4.

The only significant variable is gender, with a $p$-value of 0.043 for TRG 2. Importantly this model shows that Interval to Surgery has no significant effect on the TRG for this dataset. Controlling for other variables such as Location of Tumour, pre-op T-staging on MRI, Age, and Gender. This is further illustrated by Figure 3, showing a boxplot of TRG vs. Interval to surgery with identical distributions of TRG for patients going to surgery $<9$ weeks after completion of Long Course Chemoradiotherapy and $\geq 9$ weeks completion of Long Course Chemoradiotherapy.

\section{Discussion}

This study was performed to observe the effect of surgical interval on Tumour Regression Grade and (Complete Pathological Response). In the current study, we have observed no significant effect of interval from short course radiotherapy or long course chemoradiotherapy on Tumour Regression Grade.

Our study's finding is in complete agreement with the three years' Follow-up Results from the French Research Group of Rectal Cancer Surgery (GRECCAR), 6 randomized multi-centre trials reported that a prolonged waiting period following RCT does not influence the outcomes of rectal cancers [13].

In the current study, we classified patients into 2 groups, Less than 9 weeks vs. 9 or more than 9 weeks. In the first category, we had patients ranging from 3 to 8 weeks, and in the $2^{\text {nd }}$ category, patients ranged from 9 to 38 weeks. Following the Lyon trial published in 1999, a 6 to 7 week's interval of waiting following radio chemotherapy has been the standard of treatment [14]. In the current study, the proportion of shortcourse radiotherapy in this study which is somewhat historical, $1 / 3^{\text {rd }}$ of radiation being short course is quite high but is quite regional and was in favour back 20092015 when this study data was collected. Studies that were performed earlier reported the same proportion $[15,16]$. 


\section{Tumor Response Grade vs. Weeks post CRT}

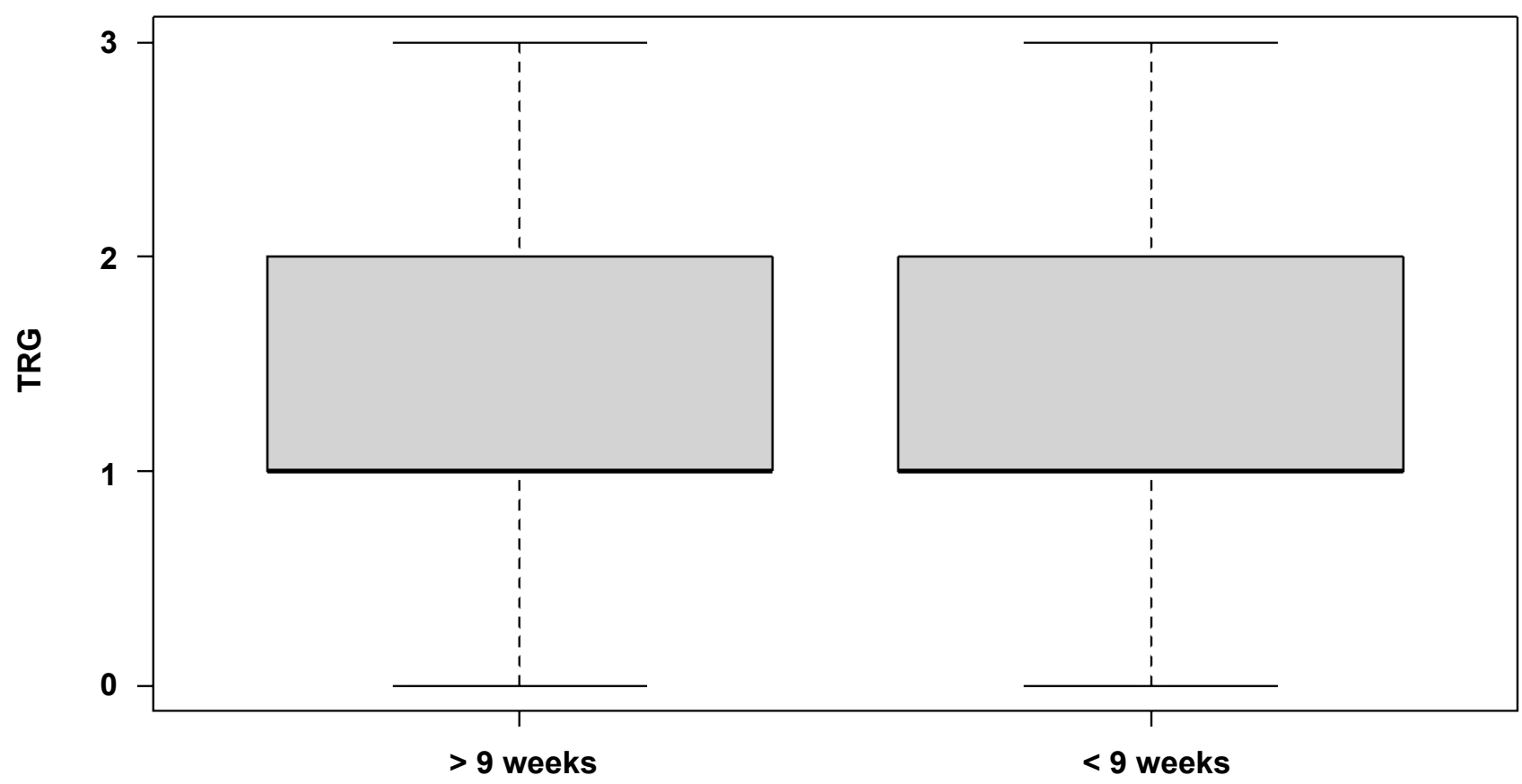

Interval to Surgery

Figure 3: Boxplot comparison of TRG vs. Interval to surgery.

According to emerging data, the prevalence of colorectal cancer in persons under the age of 50 (also known as "early-onset colorectal cancer") is increasing in high-income nations, including Australia [17-19]. Our study has observed that around $15 \%$ of the patients are below 50,25 being the youngest.

Furthermore, a 17-year follow-up study has reported no significant difference in survival rate between short course radiotherapy and long course chemoradiotherapy at $5 \mathrm{~m} \mathrm{10}, 15$, and 17 years of interval [20].

In contrast to the findings of our study, the Stockholm trial of radiography regimens for rectal cancer showed promising results. This trial reported that short-term radiography after the interval of 4-8 weeks results in the downgrading of the tumor [11]. A retrospective study observed that delaying surgery to the $15^{\text {th }}$ or $16^{\text {th }}$ week after Neoadjuvant chemoradiotherapy reported the greatest chance of complete pathological response [21].

Different results in studies could be due to the initial grading of the tumour. In some parts of the world, patients reach the surgeon at terminal stages, and chances of reoccurrence increased, and the survival rate decreased. Moreover, not every patient responds well to radiotherapy, and treatment-related toxicity can occur, lowering patients' overall and health-related quality of life [22].

Limitations include the smaller sample size, retrospective nature, and reference to the randomized control trial with which these results are concurrent.
Moreover, different grading of tumours, wide range of interval in both groups is also the limitations.

\section{Conclusion}

The main conclusion is that we could not demonstrate significance in a change in tumour grade from interval to surgery for this population in these two institutions.

\section{References}

1. Dekker E, Tanis PJ, Vleugels JLA, Kasi PM, Wallace MB (2019) Colorectal cancer. Lancet 394: 1467-1480.

2. Bray F, Ferlay J, Soerjomataram I, Siegel RL, Torre LA, et al. (2018) Global cancer statistics 2018: GLOBOCAN estimates of incidence and mortality worldwide for 36 cancers in 185 countries. CA Cancer J Clin 68: 394-424.

3. Australian Institute of Health and Welfare (2018) Cancer in Australia: Actual incidence data from 1982 to 2013 and mortality data from 1982 to 2014 with projections to 2017 . Asia Pac J Clin Oncol 14: 5-15.

4. Whiteman DC, Webb PM, Green AC, Neale RE, Fritschi L, et al. (2015) Cancers in Australia in 2010 attributable to modifiable factors: Summary and conclusions. Aust N Z J Public Health 39: 477-484.

5. Schreuders EH, Ruco A, Rabeneck L, Schoen RE, Sung JJY, et al. (2015) Colorectal cancer screening: A global overview of existing programmes. Gut 64: 1637-1649.

6. van der Stok EP, Spaander MCW, Grünhagen DJ, Verhoef C, Kuipers EJ (2017) Surveillance after curative treatment for colorectal cancer. Nat Rev Clin Oncol 14: 297-315.

7. Monson J, Weiser M, Buie W, Chang G, Rafferty J, et al. (2013) Practice parameters for the management of rectal cancer (revised). Dis Colon Rectum 56: 535-550. 
8. Smith JJ, Garcia-Aguilar J (2015) Advances and challenges in treatment of locally advanced rectal cancer. J Clin Oncol 33: $1797-1808$.

9. Calvo FA, Morillo V, Santos M, Serrano J, Gomez-Espí M, et al. (2014) Interval between neoadjuvant treatment and definitive surgery in locally advanced rectal cancer: Impact on response and oncologic outcomes. J Cancer Res Clin Oncol 140: 1651-1660.

10. Terzi C, Bingul M, Arslan N, Ozturk E, Canda AE, et al. (2020) Randomized controlled trial of 8 weeks' vs 12 weeks' interval between neoadjuvant chemoradiotherapy and surgery for locally advanced rectal cancer. Colorectal Dis 22: $279-288$.

11. Pettersson D, Lörinc $E$, Holm $T$, Iversen $H$, Cedermark $B$, et al. (2015) Tumour regression in the randomized stockholm III trial of radiotherapy regimens for rectal cancer. Br J Surg 102: $972-978$.

12. Lefevre JH, Mineur L, Kotti S, Rullier E, Rouanet $P$, et al. (2016) Effect of interval (7 or 11 weeks) between neoadjuvant radiochemotherapy and surgery on complete pathologic response in rectal cancer: A multicenter, randomized, controlled trial (GRECCAR-6). JCO 34: 37733780 .

13. Lefèvre JH, Mineur L, Cachanado $M$, Denost $Q$, Rouanet $P$, et al. (2019) Does A longer waiting period after neoadjuvant radio-chemotherapy improve the oncological prognosis of rectal cancer? Three years' follow-up results of the greccar- 6 randomized multicenter trial. Annals of Surgery 270: $747-754$.

14. Francois $Y$, Nemoz CJ, Baulieux J, Vignal J, Grandjean JP, et al. (1999) Influence of the interval between preoperative radiation therapy and surgery on downstaging and on the rate of sphincter-sparing surgery for rectal cancer: The Lyon R90-01 randomized trial. J Clin Oncol 17: 2396.

15. Stein DE, Mahmoud NN, Anné PR, Rose DG, Isenberg GA, et al. (2003) Longer time interval between completion of neoadjuvant chemoradiation and surgical resection does not improve downstaging of rectal carcinoma. Dis Colon Rectum 46: 448-453.
16. Moore HG, Gittleman AE, Minsky BD, Wong D, Paty PB, et al. (2004) Rate of pathologic complete response with increased interval between preoperative combined modality therapy and rectal cancer resection. Dis Colon Rectum 47: 279-286.

17. Patel $P$, De $P$ (2016) Trends in colorectal cancer incidence and related lifestyle risk factors in 15-49-year-olds in Canada, 1969-2010. Cancer Epidemiol 42: 90-100.

18. Gandhi J, Davidson C, Hall C, Pearson J, Eglinton T, et al. (2017) Population-based study demonstrating an increase in colorectal cancer in young patients. Br J Surg 104: 10631068.

19. Haggar FA, Preen DB, Pereira G, Holman CD, Einarsdottir $\mathrm{K}$ (2012) Cancer incidence and mortality trends in Australian adolescents and young adults, 1982-2007. BMC Cancer 12: 151

20. Cotte E, Passot G, Decullier E, Maurice C, Glehen O, et al. (2016) Pathologic response, when increased by longer interval, is a marker but not the cause of good prognosis in rectal cancer: 17-year follow-up of the Lyon R90-01 randomized trial. IJROBP 94: 544-553.

21. Sloothaak D, Geijsen DE, van Leersum NJ, Punt C, Buskens CJ, et al. (2013) Optimal time interval between neoadjuvant chemoradiotherapy and surgery for rectal cancer. Br J Surg 100: 933-939.

22. Couwenberg AM, Burbach JP, van Grevenstein WM, Smits $A B$, Consten EC, et al. (2018) Effect of neoadjuvant therapy and rectal surgery on health-related quality of life in patients with rectal cancer during the first 2 years after diagnosis. Clin Colorectal Cancer 17: 499-512.

23. Kim H (2018) Pathologic assessment and specimen quality after total mesorectal excision of rectal cancer. In: Kim $\mathrm{N}$, Sugihara K, Liang JT, Surgical treatment of colorectal cancer. Springer, Singapore. 